\title{
Abscess formation in an intrathoracic goitre
}

\author{
AHMET KARADENIZ, UĞUR HACIHANEFIOĞLU \\ From the Thoracic Surgery Centre of Yedikule, Istanbul, and the Faculty of Medicine of Istanbul, Topkapi, Turkey
}

Acute or subacute pyogenic thyroiditis is a rare condition that occurs far less commonly than other types of thyroiditis. Only a few isolated cases of acute pyogenic thyroiditis with abscess have been recorded. ${ }^{1-7}$ Its frequency relative to the operations on the thyroid is variously reported as from $0.1 \%$ to $1 \%$. We report a case of a large solitary abscess occurring in an intrathoracic goitre. This must be an extremely rare condition and we have not been able to find any similar report.

\section{Case report}

A 65-year-old man was admitted to hospital in Istanbul on 8 October 1980 with a one-month history of persistent cough, high fever, and chills despite antibiotic treatment. He had been well until he caught influenza a month previously. During the last 10 days he had developed stridor, dyspnoea, retrosternal pain, and dysphagia permitting only liquids to be swallowed. On admission he was critically ill. He had a temperature of $39^{\circ} \mathrm{C}$ and pulse rate of 130 beats/min, considerable dyspnoea, cyanosis, stridor, hoarseness, and engorgement of the neck veins.

Chest radiography showed a large mass in the mediastinum occupying the superior and mostly the right side of the mediastinum (fig 1). Films of the oesophagus showed appreciable deviation, passage of barium being almost obstructed by the mass. Lungs and heart were normal. A diagnosis of a mediastinal abscess was made and a thoracotomy was performed. There were moderately firm adhesions between mediastinum and right upper lobe. The upper part of the mass was extending to the thoracic inlet, inferiorly to the tracheal bifurcation; and on the left it was overlying the vertebral bodies, passing to the left and posterior mediastinum. The mediastinal pleura overlying the tumour was incised between the oesophagus and superior vena cava. Green fluid was aspirated from the mass, which was fluctuant on palpation. The entire wall of the abscess cavity was freed from the neighbouring structures except for the upper part of the mass attached posteriorly to the left thyroid lobe. A collar incision was made in the neck and the mass was removed through the neck with the lower part of the left lobe of the thyroid. The patient recovered uneventfully and was discharged on the 10th day after operation.

The specimen was a tense cystic mass, $10 \times 8 \times 5 \mathrm{~cm}$. The capsule was hyperaemic with some fibrin deposits and adhesions. On section, the cystic mass was generally thin walled. The large irregular abscess cavity contained a

Address for reprint requests: Department of Pathology, Faculty of Medicine of Istanbul, University of Istanbul, Topkapi, Istanbul, Turkey. purulent exudate and was lined with soft, yellow and green necrotic granular tissue. It also showed a nodular mass 1 $\mathrm{cm}$ in diameter attached to the wall at the upper pole of the cavity (fig 2).

Microscopically, the abscess cavity was lined by granulation tissue infiltrated with fibrin, neutrophils, and erythrocytes. There were areas of necrosis and a surrounding zone of fibroplasia containing small packed follicles that had little colloid and cellular infiltration with polymorphonuclear leucocytes and lymphocytes (fig 2 ). The nodular mass consisted of large follicules containing colloid and showed evidence of a very inflammatory process.

\section{Discussion}

The pathological condition present in this patient was unusual in two respects. Firstly, intrathoracic goitre is not a common condition, being reported as constituting from $\mathbf{0 . 2}$ to $3 \%$ of mediastinal tumours. The posterior location in this patient is an even more uncommon finding. ${ }^{6}$ Secondly,

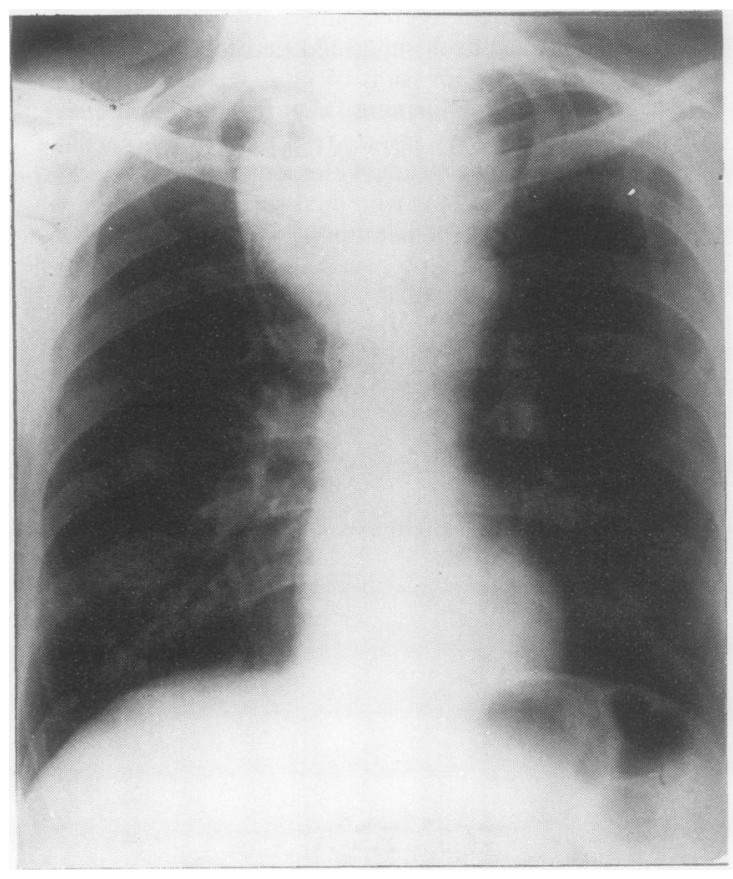

Fig 1 Chest radiograph showing a large mass in the superior mediastinum. 


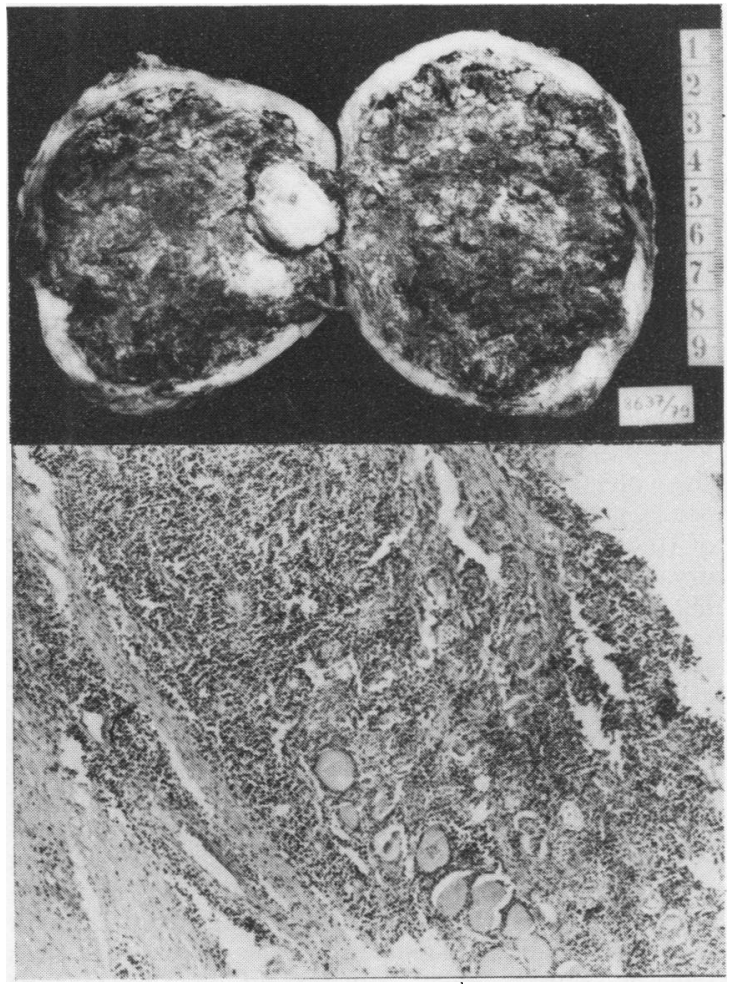

Fig 2 (a) The cut surface of the large abscess cavity containing a nodular thyroid mass attached to the wall and lined with soft necrotic tissue (b) The wall of the abscess cavity containing small thyroid follicles, acute inflammatory infiltration, and a surrounding fibrotic capsule. $H$ and $E$, original magnification $\times 120$.

the intrathoracic goitre in this case had entirely changed into an abscess cavity containing purulent exudate. This could have occurred either as suppuration of a goitre or as infection of a pre-existent thyroid cyst. The small thyroid nodule found in the abscess cavity and the rapid enlarge- ment of the mass to produce local signs indicated that the second alternative was the more likely.

The infection in this case was found only in the intrathoracic thyroid. For this reason a blood-borne infection, which has been reported as most important in such cases, ${ }^{4}$ is unlikely. Direct spread of infection by contiguity or by lymphatics from an inflammatory process in the respiratory system is a more likely possibility.

The aetiological agent was not detected. But in view of the fact that the patient had recently had an influenzal or possibly a mixed infection of the respiratory system before his addmission, Haemophilus influenzae or a nonhaemolytic or haemolytic streptococcus could well have been the cause of infection.

The interest of this case lies not only in the extreme rarity of the condition but also in the fact that diagnosis could be difficult and the lesions could be mistaken for malignant disease. Immediate surgical intervention with removal of the mass and exact diagnosis was clearly essential for our patient.

\section{References}

${ }^{1}$ Altemeier WA, Vetto RM. Acute suppurative thyroiditis. In: Werner SC, ed. The thyroid. New York: Harper and Row, 1962:838.

${ }^{2}$ Ford RV, Sanders DY, Myers RT. Thyroid abscess in a 14month-old-child. J Pediatr Surg 1973;8:943-4.

${ }^{3}$ Gaafar H, El-Garen F. Acute thyroiditis with gas formation. Laryngol Otol 1975;89:323-7.

4 Hazard JB. Thyroiditis: a review. Am J Clin Path 1955;25:28998.

${ }^{5}$ Hoffman E. Intrathoracic goitre. Br J Surg 1955;43:310-14.

' Lafaye M, Gaillard de Collogny L, Bruneaud D, et al. Thyroidites aigués a pyogenes et abcès de la thyroide. J Fr Otorhinolaryngol 1975;24:291-8.

${ }^{7}$ Mann $\mathrm{CH}$. Thyroid abscess in a 3.5-year-old child. Arch Otolaryngol 1977;103:299-300. 